\title{
Enhanced Photocurrent Generation by Electron Hopping through Regularly-Arranged Chromophores in a Helical Peptide Monolayer
}

\author{
By Tomoyuki MorITA, ${ }^{*}$ Kazuyuki YANAGISAWA, and Shunsaku KIMURA
}

\begin{abstract}
Novel 310 -helical peptides having a disulfide group at the $N$-terminal and carrying naphthyl groups at the side chains in a linear arrangement were synthesized, those are 9mer, $18 \mathrm{mer}$, and $27 \mathrm{mer}$ peptides with three, six, and nine naphthyl groups, respectively. Spectroscopic measurements of the peptide solutions showed that there was no interaction between the neighboring naphthyl groups. 310 -Helical conformation was confirmed by circular dichroism spectroscopy and computational molecular modeling. The peptides were self-assembled on gold by an Au-S linkage, and the defect sites in the self-assembled monolayers (SAMs) were filled up with dodecanethiol. Cyclic voltammetry, ellipsometry, and infrared reflection-absorption spectroscopy studies on the SAMs showed that the peptides formed the densely-packed monolayers with vertical orientation. Upon photoexcitation of the naphthyl groups in an aqueous solution containing electron donors, the monolayer generated an anodic photocurrent by photoinduced electron transfer from the electron donor via the naphthyl groups to gold. The longest 27mer peptide generated the largest photocurrent among the peptides. Theoretical simulations successfully demonstrated that the helix scaffold with many naphthyl groups in a linear arrangement was effective to suppress quenching of the excited naphthyl group by gold due to the elongation of the helix length, and to promote electron hopping among the naphthyl groups enabling long-range electron transfer from the distant naphthyl group to gold, eventually realizing an efficient photocurrent generation molecular system.

KEY WORDS: Helical Peptide / Chromophore / Self-assembled Monolayer / Electron Transfer / Photocurrent Generation / Electron

Hopping /
\end{abstract}

In natural photosynthetic systems, solar photons are harvested by antenna chromophores, the collected photoenergy induces electron transfer at the reaction center, and the generated charges are separated along electron-transport chromophores. ${ }^{1,2}$ Those chromophores are sophisticatedly arranged inside protein assemblies, and this regular arrangement is essential to the highly efficient light harvesting and charge separation. Assemblies of helices (mainly $\alpha$-helix and occasionally $3_{10}$-helix) are often found in naturally occurring proteins like in the core region of the photosynthetic protein assemblies, and they provide a framework to locate chromophores in a regular and rational manner. The reason can be easily understood with the rigidity and periodicity of a helix itself and regularity of its self-assemblies. Moreover, it has been proposed that the helical structure should play a more central role in the charge separation process by electron mediation with the amide groups and control of electron transfer direction with the macro dipole moment. ${ }^{3,4}$ The tunneling decay factor along model helical peptides is reported to be $0.5-0.7 \AA^{-1}$ determined by studies on photoinduced electron transfer in a donor-peptide-acceptor triad and on molecular conduction at a metal-peptide-metal junction by scanning tunneling spectroscopy. ${ }^{5-7}$ The smaller decay factor compared to that of alkane chains $\left(0.9-1.1 \AA^{-1}\right)$ indicates that a helical peptide is a better electron mediator. ${ }^{8-11}$ The acceleration of photoinduced electron transfer by the dipole moment was also demonstrated in solution as well as in a selfassembled monolayer. ${ }^{12-16}$ Therefore, helical peptides are considered to be an ideal component for molecular electronics systems.

Photocurrent generation by molecular thin layers prepared on metal is one typical function of such molecular systems, and it can be taken as an artificial mimic of natural photosynthesis. Self-assembled monolayers (SAMs) on gold composed of thiol-terminated molecules have been extensively studied for photocurrent generation in solution. ${ }^{14-33} \mathrm{~A}$ wide variety of molecules from simple sensitizer-terminated molecules, ${ }^{14-17,21-24,28,29,31-33}$ sensitizer-donor ${ }^{19,26}$ or sensitizeracceptor $^{18,20,30}$ dyads, to advanced donor-sensitizer-acceptor triads, ${ }^{25,27}$ have been examined to improve the efficiency and yield of photocurrent generation. Components and construction of the molecular architectures are also various, such as utilizing noncovalent bonding to prepare a molecular layer, ${ }^{29,30,32}$ using a gold nanoparticle as an electron acceptor, ${ }^{28,31}$ and even introducing a photoenergy-harvesting chromophore array. ${ }^{24,27,29,30}$ Meanwhile, we have exclusively utilized sensitizer-terminated helical peptides as components for photocurrent generation systems and reported the advantages of well-defined structures of the peptides and their self-assemblies, and the superior electron mediation and dipole moment effect mentioned above. ${ }^{14-16,24,33}$ For efficient photocurrent generation, the distance between a sensitizer and gold is

Department of Material Chemistry, Graduate School of Engineering, Kyoto University, Kyoto-Daigaku-Katsura, Nishikyo-ku, Kyoto 615-8510, Japan *To whom correspondence should be addressed (Tel: +81-75-383-2404, Fax: +81-75-383-2401, E-mail: morita@ peptide.polym.kyoto-u.ac.jp). 


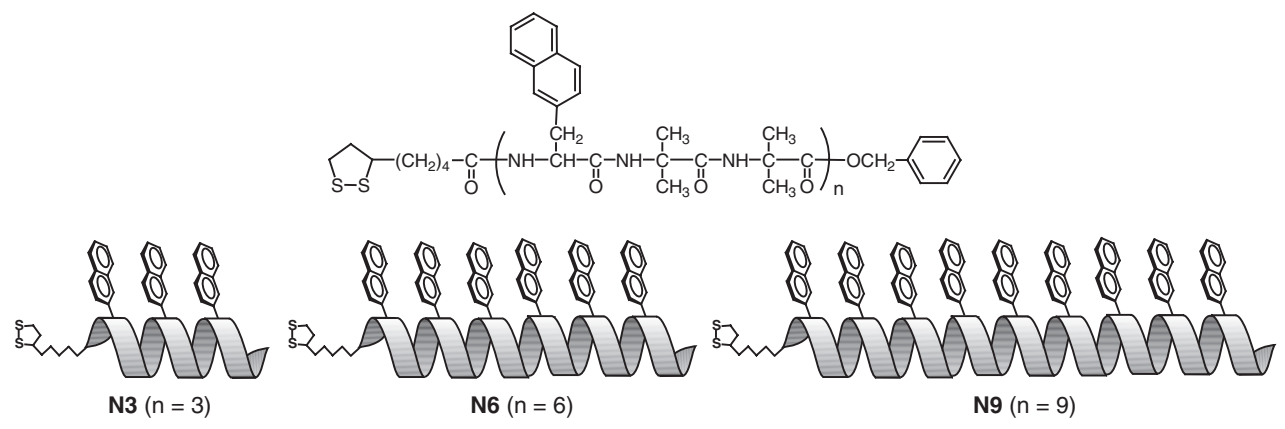

Figure 1. Chemical structures and schematic illustrations of N3, N6, and N9.

important. For example, in the case of anodic photocurrent generation by a monolayer composed of sensitizer-terminated molecules with an electron donor in the solution phase, if the sensitizer is tethered on the surface by a short linker, its photoexcitation energy is readily wasted by energy transfer to gold to hinder the desired electron transfer process from the donor to sensitizer. ${ }^{21}$ On the other hand, with elongation of the linker between the sensitizer and gold, the unfavorable energy transfer will be minimized but the electron transfer process from the reduced sensitizer by the donor to gold is slowed down exponentially with the distance eventually to suppress photocurrent generation.

One resolution of this dilemma is close arrangement of multiple chromophores between the solution phase and the gold surface, which will help an electron travel over a long distance by hopping among the chromophores. In our previous study, we reported photocurrent generation by a monolayer composed of a 310 -helical nonapeptide carrying three naphthyl (Nap) groups at side chains in a linear arrangement (N3, Figure 1). ${ }^{33} 3_{10}$-helix makes one turn with three residues and peptide sequences of high content of $\alpha$-aminoisobutyric acid (Aib) favor the 310 -helical conformation. ${ }^{34-38}$ Therefore, repetition of a 2-naphthylalanine-Aib-Aib sequence can locate the Nap groups in a linear arrangement along the helix axis. The peptide SAMs were prepared on gold with a covalent linkage between gold and a disulfide group introduced at the peptide $\mathrm{N}$-terminal. Photocurrent generation in an aqueous solution containing triethanolamine (TEOA, sacrifice electron donor) was studied with photoexcitation of the Nap groups, and it was demonstrated that electron hopping among the naphthyl groups facilitated the electron transfer from the aqueous phase to gold to promote anodic photocurrent generation.

The $3_{10}$-helix as a scaffold for the Nap groups at every third residue is able to arrange the Nap groups by a spacing of $6 \AA$, which has a quantitative meaning for efficient photocurrent generation. When the Nap groups near the gold are photoexcited, the photoenergy may be dissipated by intrinsic deactivations and photoenergy transfer to gold. But photoenergy migration among the Nap groups side by side will compete with the deactivation processes, and expectedly overcome them to transfer the photoenergy to the Nap group at the $C$-terminal exposed to the aqueous phase, where the reaction with the donor is available. The interchromophore distance between neighboring Nap groups along the $3_{10}$ helix is $c a$. $6 \AA$, which is shorter than the critical distance for this resonant Nap-Nap photoenergy migration via a dipole-dipole interaction $^{39}$ (8.2 $\AA$ ), expecting facile photoenergy migration. But it is longer than a distance of $3-4 \AA$, at which they may form a dimer in the ground or excited state, to avoid formation of unfavorable trapping sites for migrating photoenergy or hopping electrons.

To further extend this idea, 18 mer 310 -helical peptide carrying six naphthyl groups and 27mer carrying nine naphthyl groups (N6 and N9, Figure 1) are examined in the present study. Our expectation for the elongated helices is that the long helix will suppress the quenching possibility of the excited naphthyl group by gold and accordingly increase the yield of production of Nap anion radical upon photoexcitation. A negative side of helix elongation may be a long distance of electron transfer from the donor to gold. But the regularly arranged Nap groups along the helix are expected to act as the hopping sites to transport the electron (Nap anion radical) generated at the $C$-terminal to gold for efficient photocurrent generation.

In this study, the $3_{10}$ helical peptides in a series of helical lengths were synthesized by the liquid-phase method, and their electronic structures and conformation were studied by absorption, fluorescence, and circular dichroism (CD) spectroscopy as well as computational geometry optimization. SAMs were prepared on gold and monolayer defects were filled up with dodecanethiol, ${ }^{40}$ and the monolayers were characterized by cyclic voltammetry (CV), ellipsometry, and infrared reflection-absorption spectroscopy (IRRAS). The photocurrent generation by the SAMs was investigated in an aqueous solution containing TEOA as the donor and the experimental results were discussed on the basis of theoretical simulations.

\section{EXPERIMENTAL}

\section{Synthesis of Helical Peptides}

N3 was synthesized according to the literature. ${ }^{33}$ N6 and N9 were synthesized as follows.

N6. The benzyl group of Boc-(NapAla-Aib-Aib) $)_{3}-\mathrm{OBzl}$ (BN3B, intermediate product for $\mathrm{N} 3,100 \mathrm{mg}$ ) was removed by hydrogenation in methanol $(6 \mathrm{~mL})$ under $\mathrm{H}_{2}$ atmosphere in the 
presence of ammonium formate $(125 \mathrm{mg}$ ) and $10 \mathrm{wt} \% \mathrm{Pd} / \mathrm{C}$ $(125 \mathrm{mg})$ at room temperature for $3 \mathrm{~h}$. After reaction, $\mathrm{Pd} / \mathrm{C}$ was filtered out, the solvent was evaporated, and the residue was purified by a Sephadex LH20 column with methanol as eluent to afford Boc-(NapAla-Aib-Aib) ${ }_{3}-\mathrm{OH}(\mathrm{BN} 3 \mathrm{OH})$. On the other hand, the Boc group of $\mathrm{BN} 3 \mathrm{~B}(26 \mathrm{mg})$ was removed by treatment with $4 \mathrm{~N} \mathrm{HCl} /$ dioxane $(0.43 \mathrm{~mL})$ at room temperature for $30 \mathrm{~min}$. After reaction, the solvent was evaporated, and the residue was washed with $n$-hexane and dried in a vacuum desiccator loaded with $\mathrm{NaOH}$ to afford $\mathrm{HCl} \mathrm{H}$ (NapAla-Aib-Aib) $)_{3}-\mathrm{OBzl} \quad(\mathrm{HN} 3 \mathrm{~B}) . \quad \mathrm{BN} 3 \mathrm{OH} \quad(38 \mathrm{mg})$ and $\mathrm{HN} 3 \mathrm{~B}$ (37 mg) were dissolved in DMF, $O$-(7-azabenzotriazol-1-yl)-1,1,3,3-tetramethyluronium hexafluorophosphate (HATU) (14 mg) and $N, N$-diisopropylethylamine (DIEA) $(15 \mu \mathrm{l})$ were added, and the solution was stirred under $\mathrm{N}_{2}$ atmosphere at $0{ }^{\circ} \mathrm{C}$ for $3 \mathrm{~h}$ and thereafter at room temperature for $24 \mathrm{~h}$. The solvent was evaporated, and the residue was repeatedly washed with methanol to afford Boc-(NapAla-AibAib) 6 -OBzl (BN6B, $29 \mathrm{mg}$ ). BN6B was then treated with anisole $(20 \mu \mathrm{l})$ and trifluoroacetic acid $(200 \mu \mathrm{l})$ at room temperature for $30 \mathrm{~min}$ to remove the Boc group. The solvent was evaporated, and the residue was washed with diisopropyl ether to afford TFA H-(NapAla-Aib-Aib) 6 -OBzl (HN6B). DL$\alpha$-Lipoic acid (9 mg) and HN6B (20 mg) were dissolved in DMF, HATU $(19 \mathrm{mg})$ and DIEA $(15 \mu \mathrm{l})$ were added, and the solution was stirred under $\mathrm{N}_{2}$ atmosphere at $0{ }^{\circ} \mathrm{C}$ for $1 \mathrm{~h}$ and thereafter at room temperature for $2 \mathrm{~h}$. The solvent was evaporated and the residue was purified by a Sephadex LH20 column with chloroform/methanol $(1 / 1 \mathrm{v} / \mathrm{v})$ as eluent to afford the final product (N6, 6mg). TLC: $R_{\mathrm{f}}$ (chloroform/ methanol/acetic acid $=95 / 5 / 3 \mathrm{v} / \mathrm{v} / \mathrm{v})=0.24, R_{\mathrm{f}}$ (chloroform $/$ methanol $=20 / 1 \mathrm{v} / \mathrm{v})=0.39 .{ }^{1} \mathrm{H} \mathrm{NMR}\left(\mathrm{CDCl}_{3}, 400\right.$ $\mathrm{MHz}): \delta(\mathrm{ppm})$ 0.98-1.72 (79H, m, Aib- $\mathrm{CH}_{3}, \mathrm{SSCH}_{2} \mathrm{CH}_{2} \mathrm{CH}-$ $\left.\left(\mathrm{CH}_{2}\right)_{3} \mathrm{CH}_{2} \mathrm{CO}\right), 1.76,2.28\left(2 \mathrm{H}, \mathrm{m}, \mathrm{SSCH}_{2} \mathrm{CH}_{2} \mathrm{CH}\left(\mathrm{CH}_{2}\right)_{3}-\right.$ $\mathrm{CH}_{2} \mathrm{CO}$ ), 2.19 (2H, brs, $\left.\mathrm{SSCH}_{2} \mathrm{CH}_{2} \mathrm{CH}\left(\mathrm{CH}_{2}\right)_{3} \mathrm{CH}_{2} \mathrm{CO}\right), 2.93-$ 3.55 (15H, brm, $\mathrm{SSCH}_{2} \mathrm{CH}_{2} \mathrm{CH}\left(\mathrm{CH}_{2}\right)_{3} \mathrm{CH}_{2} \mathrm{CO}$, NapAla-C ${ }^{\beta} \mathrm{H}_{2}$, $\left.\mathrm{SSCH}_{2} \mathrm{CH}_{2} \mathrm{CH}\left(\mathrm{CH}_{2}\right)_{3} \mathrm{CH}_{2} \mathrm{CO}\right), 4.24$ (6H, brm, NapAla- ${ }^{\alpha} H$ ), $5.07\left(2 \mathrm{H}, \mathrm{s}, \mathrm{OCH}_{2} \mathrm{C}_{6} \mathrm{H}_{5}\right), 6.88-8.26(65 \mathrm{H}, \mathrm{brm}$, naphthyl- $H$, $\mathrm{OCH}_{2} \mathrm{C}_{6} \mathrm{H}_{5}$, NapAla-NH, Aib-NH). MS (FAB, matrix; nitrobenzylalcohol): $m / z 2523$ (calcd for $\mathrm{C}_{141} \mathrm{H}_{170} \mathrm{~N}_{18} \mathrm{NaO}_{20} \mathrm{~S}_{2}$ $\left[(\mathrm{M}+\mathrm{Na})^{+}\right] m / z$ 2523.22).

N9. The benzyl group of $\mathrm{N} 3(22 \mathrm{mg})$ was removed by treatment with $5 \% \mathrm{NaOH}$ in methanol/dichloromethane/water $(2 / 1 / 1 \mathrm{v} / \mathrm{v} / \mathrm{v}, 1 \mathrm{~mL})$ at $50{ }^{\circ} \mathrm{C}$ for $1 \mathrm{~h}$. Chloroform was added to the solution, and washed with a $4 \% \mathrm{KHSO}_{4}$ aqueous solution. The organic phase was collected, and the solvent was evaporated. The product and HN6B $(39 \mathrm{mg})$ were dissolved in chloroform $(3 \mathrm{~mL})$, HATU $(24 \mathrm{mg})$ and DIEA $(17 \mu \mathrm{l})$ were added, and the solution was stirred under $\mathrm{N}_{2}$ atmosphere at $0{ }^{\circ} \mathrm{C}$ for $10 \mathrm{~min}$ and thereafter at room temperature for $24 \mathrm{~h}$. The solvent was removed, and washed successively with methanol five times and with tetrahydrofuran to afford the final product (N9, $20 \mathrm{mg}$ ). TLC: $R_{\mathrm{f}}$ (chloroform/methanol/acetic acid $=95 / 5 / 3 \quad \mathrm{v} / \mathrm{v} / \mathrm{v})=0.11, R_{\mathrm{f}} \quad($ chloroform $/$ methanol $=$ $10 / 1 \mathrm{v} / \mathrm{v})=0.50 .{ }^{1} \mathrm{H} \mathrm{NMR}\left(\mathrm{CDCl}_{3}, 400 \mathrm{MHz}\right): \delta(\mathrm{ppm})$ 0.80-1.95 (117H, brm, Aib- $\left.\mathrm{CH}_{3}, \mathrm{SSCH}_{2} \mathrm{CH}_{2} \mathrm{CH}\left(\mathrm{CH}_{2}\right)_{4} \mathrm{CO}\right)$,
2.50 (1H, brm, $\left.\mathrm{SSCH}_{2} \mathrm{CH}_{2} \mathrm{CH}\left(\mathrm{CH}_{2}\right)_{4} \mathrm{CO}\right), 3.05-3.40(21 \mathrm{H}$, brm, $\mathrm{SSCH}_{2} \mathrm{CH}_{2} \mathrm{CH}\left(\mathrm{CH}_{2}\right)_{4} \mathrm{CO}$, NapAla-C ${ }^{\beta} \mathrm{H}_{2}, \mathrm{SSCH}_{2} \mathrm{CH}_{2} \mathrm{CH}-$ $\left.\left(\mathrm{CH}_{2}\right)_{4} \mathrm{CO}\right), 4.17\left(9 \mathrm{H}\right.$, brm, NapAla- $\left.{ }^{\alpha} H\right), 5.01(2 \mathrm{H}, \mathrm{m}$, $\left.\mathrm{OCH}_{2} \mathrm{C}_{6} \mathrm{H}_{5}\right), 7.05-8.30$ (105H, brm, naphthyl- $H, \mathrm{OCH}_{2} \mathrm{C}_{6} \mathrm{H}_{5}$, NapAla-N $H$, Aib-N $H$ ). MS (MALDI-TOF, matrix; dithranol): $m / z \quad 3623$ (calcd for $\mathrm{C}_{204} \mathrm{H}_{245} \mathrm{~N}_{27} \mathrm{NaO}_{29} \mathrm{~S}_{2}\left[(\mathrm{M}+\mathrm{Na})^{+}\right] m / z$ 3625.8), $m / z, 3639$ (calcd for $\mathrm{C}_{204} \mathrm{H}_{245} \mathrm{~N}_{27} \mathrm{KO}_{29} \mathrm{~S}_{2}\left[(\mathrm{M}+\mathrm{K})^{+}\right.$] $m / z$ 3641.8).

\section{Spectroscopy in Solution}

The absorption and fluorescence spectra of the peptides were recorded on a Shimadzu UV-2450PC spectrometer and a Jasco FP-6600 fluorometer, respectively, at the naphthyl concentration of $7.4 \times 10^{-6} \mathrm{M}$. The solvent was chloroform for N3 and N6 but chloroform/trifluoroethanol (TFE)/hexafluoroisopropanol (HFIP) $(40 / 1 / 1 \mathrm{v} / \mathrm{v} / \mathrm{v})$ for N9 because N9 is not soluble in pure chloroform. The excitation wavelength for fluorescence spectra was $278 \mathrm{~nm}$. The CD spectra were measured in ethanol/HFIP $(1 / 1 \mathrm{v} / \mathrm{v})$ for N3 or pure HFIP for N6 and N9 on a JASCO J-600 CD spectropolarimeter with an optical cell of a $0.1 \mathrm{~cm}$ optical path length. The naphthyl concentration was $1.2-1.9 \times 10^{-4} \mathrm{M}$. All the concentrations were determined from the absorbance at $278 \mathrm{~nm}$ using the molar extinction coefficient of the naphthyl group at $278 \mathrm{~nm}$ $(13,550)$. All measurements were carried out at room temperature.

\section{Molecular Modeling}

The initial geometries of the respective peptides were generated by a Fujitsu CAChe WorkSystem 6.1.1 software. The dihedral angles of the peptide backbone were set to be $\omega=180^{\circ}, \phi=-60^{\circ}$, and $\psi=-30^{\circ}$, respectively, to produce a 310 -helical structure. Each initial geometry was then optimized by the Molecular Mechanics program 2 (MM2) method and the semiempirical Austin Model 1 (AM1) method in the MOPAC 2002 package on the same software.

\section{Preparation of Self-assembled Monolayers}

A slide glass $(76 \mathrm{~mm} \times 5 \mathrm{~mm})$ was cleaned with sulfuric acid for $3 \mathrm{~h}$, thoroughly rinsed with methanol and distilled water, and dried in vacuum for $15 \mathrm{~min}$. Chromium and then gold $(99.99 \%)$ were deposited on the glass by the vapor deposition method. The thicknesses of the chromium and gold layers were 300 and $2000 \AA$, respectively, monitored by a quartz oscillator. The freshly-prepared gold substrate was incubated in a solution of the peptide (ca. $0.1 \mathrm{mM})$ at room temperature for $24 \mathrm{~h}$. The solvent systems were ethanol for N3, ethanol/chloroform (24/1) for N6, and chloroform/TFE/HFIP $(40 / 1 / 1)$ for $\mathrm{N} 9$, respectively. After the immersion, the substrate was rinsed rigorously with appropriate solvents, dried in a steam of dry nitrogen gas, and dried under vacuum for 10 $15 \mathrm{~min}$. The rinsing solvents were ethanol for N3, chloroform followed by ethanol for N6, and chloroform/TFE/HFIP (40/1/1) followed by chloroform for N9, respectively. The monolayer-modified substrate was then placed into a test tube, where the test tube was placed into another bigger test tube 
with dodecanethiol inside ( $c a .2 \mathrm{~mL}$ ), and the temperature of the system was kept at $80^{\circ} \mathrm{C}$ for $2 \mathrm{~h} .{ }^{40}$ Then the substrate was rinsed rigorously with ethanol, dried in a steam of dry nitrogen gas, and dried under vacuum for 10-15 min.

\section{Cyclic Voltammetry}

Cyclic voltammograms were obtained with using a BAS model 604 voltammetric analyzer at room temperature. A standard three-electrode setup was used with the monolayermodified substrate as the working electrode, $\mathrm{Ag} / \mathrm{AgCl} / 3 \mathrm{M}$ $\mathrm{NaCl}$ aq. as the reference electrode, and a platinum wire as the auxiliary electrode in a sealed glass vessel. The solution was a $1 \mathrm{mM} \mathrm{K}_{4}\left[\mathrm{Fe}(\mathrm{CN})_{6}\right]$ in $1 \mathrm{M} \mathrm{KCl}$ aqueous solution, and it was bubbled with nitrogen gas for $10 \mathrm{~min}$ before measurement. The sweep rate was set at $100 \mathrm{mV} \mathrm{s}^{-1}$.

\section{Ellipsometry}

The thicknesses of the peptide monolayers on gold were determined by a MIZOJIRI DHA-OLX/S autoellipsometer at room temperature. A helium-neon laser of $632.8 \mathrm{~nm}$ was used as the incident light, and the incident angle was set at $65^{\circ}$. The thickness of the monolayer was calculated automatically by using an equipped program. In the calculation, the complex optical constant of the monolayer was assumed to be $1.50+0.00 i$. The thickness was obtained as the average on more than 5 different regions of the monolayer.

\section{IRRAS Measurements}

The IRRAS spectra of the peptide monolayers on gold were recorded on a Nicolet Magna 850 Fourier transform infrared spectrometer with a Harrick RMA-1DG/VRA reflection attachment at room temperature. The incident light is not polarized and its incident angle was set at $85^{\circ}$ from the surface normal. The number of interferogram accumulations was 500 . The molecular orientation of the helical peptide was determined from of the amide I/amide II absorbance ratio in the IRRAS spectrum according to the equation shown below under the assumption of uniform orientation of the helix axis around the surface normal. ${ }^{41,42}$

$$
\begin{gathered}
I_{1} / I_{2}=1.5\left(\left(3 \cos ^{2} \gamma-1\right)\left(3 \cos ^{2} \theta_{1}-1\right)+2\right) \\
/\left(\left(3 \cos ^{2} \gamma-1\right)\left(3 \cos ^{2} \theta_{2}-1\right)+2\right)
\end{gathered}
$$

$I_{\mathrm{i}}, \gamma$, and $\theta_{\mathrm{i}} \quad \mathrm{i}=1$ or 2 corresponding to amide $\mathrm{I}$ or amide II) represent the observed absorbance, the tilt angle of helical axis from the surface normal, and the angle between the transition moment and the helix axis, respectively. The values of the $\theta_{1}$ and $\theta_{2}$ were taken to be $39^{\circ}$ and $83^{\circ}$, respectively, for $310^{\text {-helical conformation. }}{ }^{38,43}$ The thicknesses of the monolayers were estimated by (molecular length) $\times \cos \gamma$. The molecular lengths of the peptides were calculated by the helix length and the length of the rest parts. The helix lengths were estimated with $2.0 \AA$ per residue for a 310 -helix ${ }^{44}$ (18 $\AA$ for N3, $36 \AA$ for N6, and $54 \AA$ for N9). Since the conformation of the parts other than the helix is unknown, the half of the length of the longest extended conformation was used as approximation. The longest length was determined by geometry optimization of a virtual compound, Au-lipoic acid benzyl ester, by the MM2 and AM1 method to be $c a$. $14 \AA$. Therefore, the molecular lengths are $25 \AA$ for N3, $43 \AA$ for N6, and $61 \AA$ for N9, respectively.

\section{Photocurrent Generation Experiments}

Photocurrent measurements were carried out at an applied potential of $0 \mathrm{~V}$ on gold with respect to the reference electrode at room temperature using the three-electrode setup described above. The solution was a $0.05 \mathrm{M}$ TEOA and $0.1 \mathrm{M} \mathrm{Na}_{2} \mathrm{SO}_{4}$ aqueous solution. The monolayer-modified substrate was photoirradiated with a Jasco Xe lamp $(500 \mathrm{~W})$ equipped with an Asahi Spectra MX0280 band pass filter (fwhm $10 \mathrm{~nm}$ ). The light intensity was measured to be $1.5 \times 10^{13}$ photons/s by a potassium ferrioxalate actinometry. ${ }^{45}$ The irradiation area of the electrode was $c a .0 .2 \mathrm{~cm}^{2}$. The time profile of the current was recorded. The quantum yield for photocurrent generation was calculated by dividing the number of the electron flowed by the number of photons absorbed by the Nap groups per unit time. The latter value was calculated on the basis of molar extinction coefficient, the surface density of Nap group, and the light intensity. The surface density of the Nap groups was estimated from the IRRAS tilt angle and the molecular crosssectional area of $1.30 \mathrm{~nm}^{2}$ which was determined by molecular modeling. Simulations of the photocurrent generation was carried out by a Wolfram Mathematica program (ver. 5.0).

\section{RESULTS AND DISCUSSION}

\section{Spectroscopy}

N3, N6, and N9 were synthesized by the liquid-phase method. To study the electronic interactions between the neighboring Nap groups, absorption and fluorescence spectroscopic measurements were carried out in solution. The absorption spectra of N3 and N6 in chloroform and N9 in chloroform/TFE/HFIP (40/1/1) are shown in Figure 2 (left panel). N9 is not soluble in pure chloroform. Characteristic absorption peaks for a naphthalene monomer were observed at $271 \mathrm{~nm}, 278 \mathrm{~nm}$, and $288 \mathrm{~nm}$ (shoulder). ${ }^{46}$ The fluorescence spectra recorded in the same solvent systems are shown in Figure 2 (middle). Only monomer emission of naphthalene was observed at $330 \mathrm{~nm}, 338 \mathrm{~nm}$, and $354 \mathrm{~nm}$ (shoulder), ${ }^{46}$ but free from excimer emission $(>400 \mathrm{~nm}$ ). These results indicate that there is no interaction between the neighboring Nap groups either in the ground state or in the excited state, and suggest that the Nap groups are regularly spaced along the helix. The fluorescence intensity is larger in the order of N9, N6, and N3. The intensity ratio of N9:N6:N3 roughly agrees with 8:5:2. It is considered that the disulfide group at the $N$-terminal quenches the neighboring Nap group.

Next, CD spectroscopy was performed to study the conformation of the peptides in ethanol/HFIP for N3 and pure HFIP for N6 and N9 (Figure 2 right). A pair of strong splitting peaks with a positive sign at a shorter wavelength and a negative sign at a longer wavelength were observed. The center wavelengths were $220 \mathrm{~nm}$ for N3 while $215 \mathrm{~nm}$ for N6 and N9, 

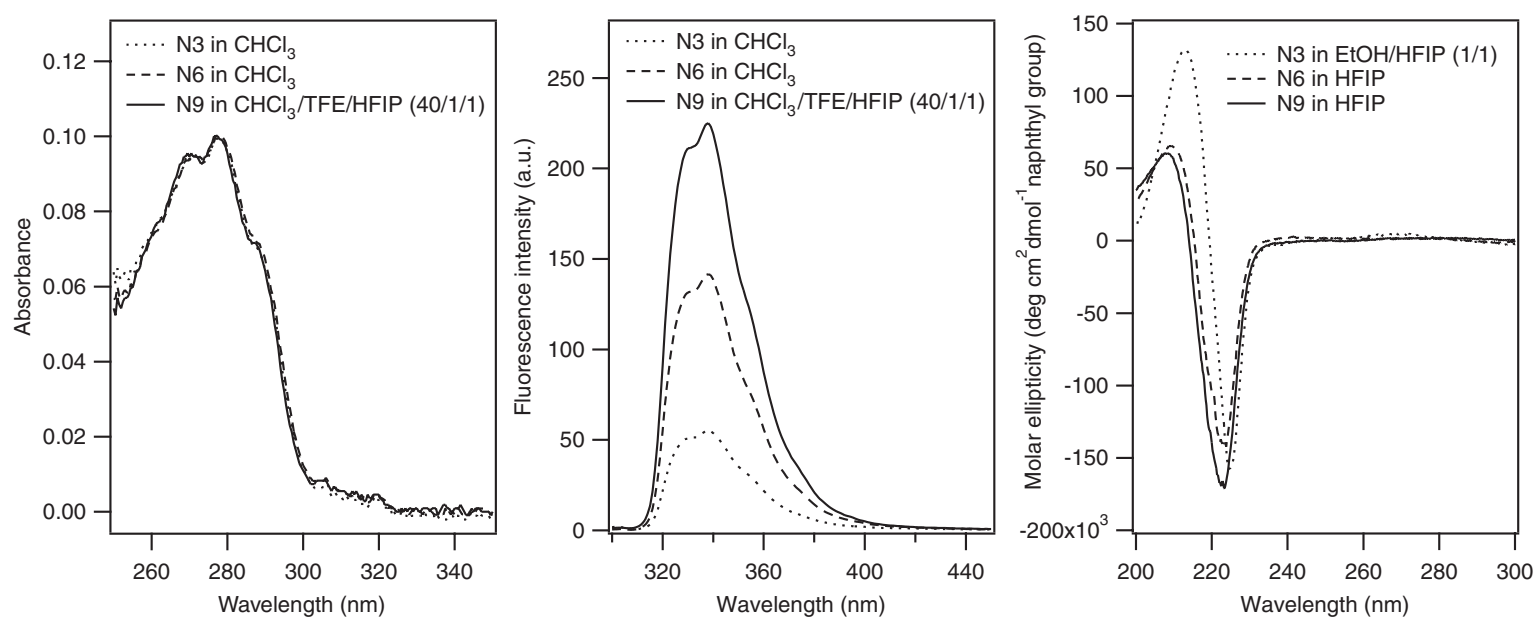

Figure 2. Absorption (left panel), fluorescence (middle), and CD (right) spectra of N3 (dotted line), N6 (dashed line), and N9 (solid line) in solution. The solvents are indicated in the figures.

top view

N3

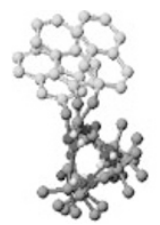

N6

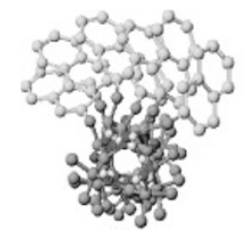

N9

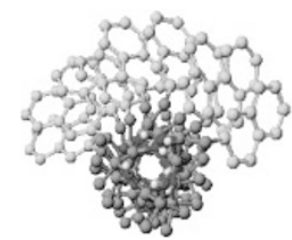

side view
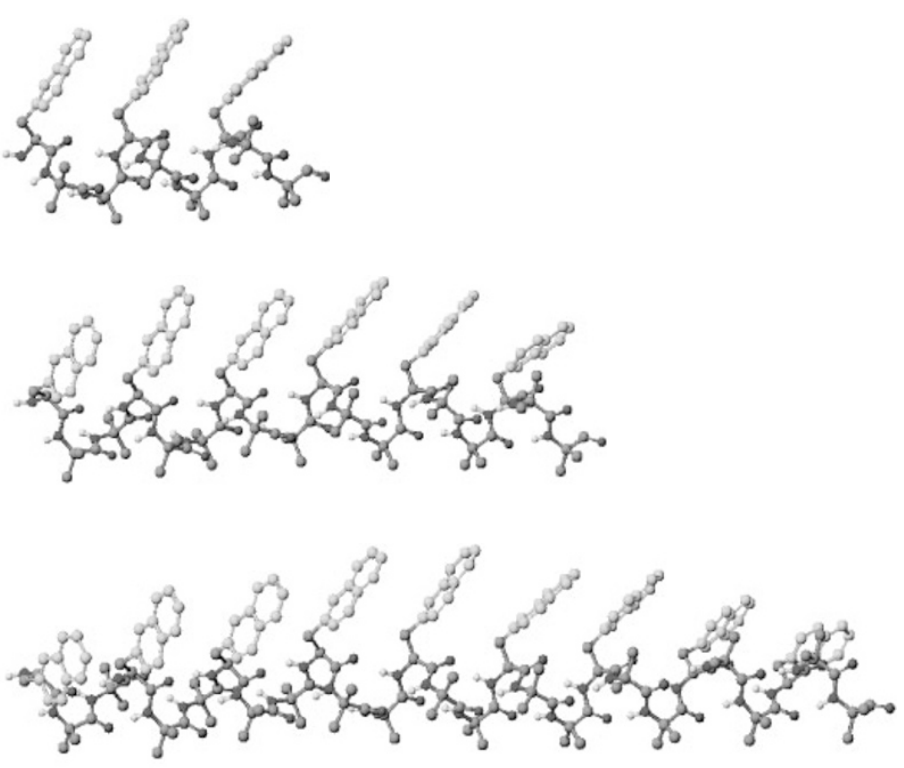

Figure 3. Optimized geometries of N3, N6, and N9. The naphthyl carbons are shown in pale color and the hydrogen atoms and the protecting groups at the Nand $C$-terminals are hidden for clarity.

and the slight difference is probably due to the different solvent systems. The ${ }^{1} \mathrm{Bb}$ transition of Nap group along the molecular long axis is located at $225 \mathrm{~nm} .{ }^{47,48}$ On the basis of the exciton chirality method, ${ }^{47-52}$ the observed CD peak indicates that the Nap groups are closely arranged in a counterclockwise manner from the view along the helix axis. The plausible peptide conformation was estimated by computational molecular modeling. The initial geometry was generated using typical dihedral angles for a 310 -helix, and the geometry was optimized by the MM2 and AM1 methods. The calculations gave a $310^{-}$ helical structure with a counterclockwise arrangement of the Nap groups as an energy-minimized geometry, which agrees with the $\mathrm{CD}$ observation (Figure 3 ). It is thus concluded that

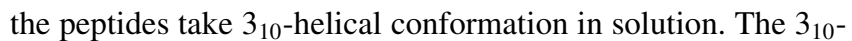

helical conformation of $\mathrm{N} 3$ has been confirmed by a ${ }^{1} \mathrm{H}$ NMR study in $\mathrm{CDCl}_{3}$ on the basis of the number of free amide protons at the $\mathrm{N}$-terminal, which was evaluated from large chemical shift changes with addition of DMSO-d6 as a hydrogen-bond acceptor. ${ }^{33}$ The similar measurements could not be carried out for N6 and N9 because of complicated nature of the amide proton region and broadened peaks due to the lower solubility of the peptides.

\section{Monolayer Characterizations}

The peptide SAMs were prepared by immersion of a gold substrate in the peptide solution. The solvent systems adopted for the SAM preparation were optimized in terms of the monolayer quality to be pure ethanol for N3, ethanol/chloro- 

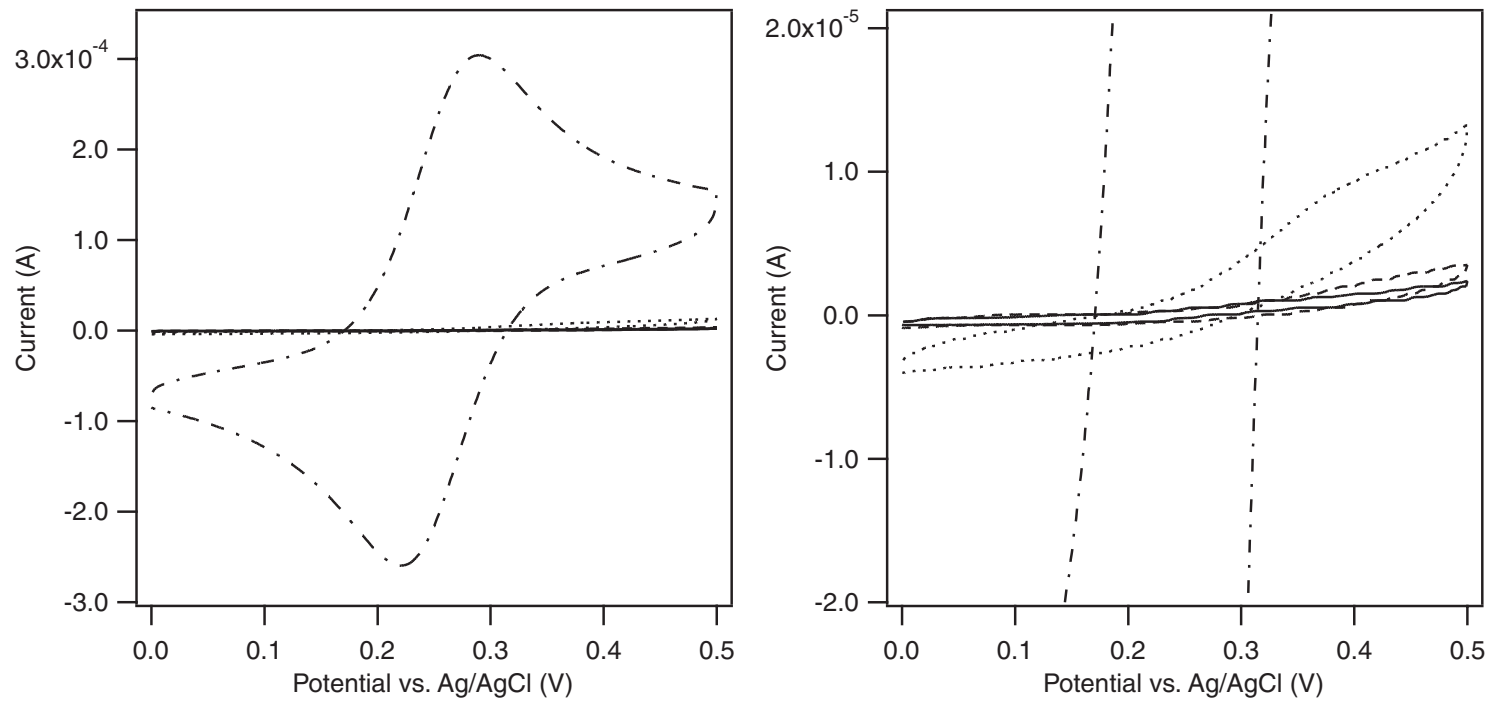

Figure 4. Cyclic voltammograms of a bare gold (dash-dot line), the $\mathrm{N} 3$ (dotted), $\mathrm{N} 6$ (dashed), and $\mathrm{N} 9$ (solid) $\mathrm{SAMs}$ in a $1 \mathrm{mM} \mathrm{K}_{4}\left[\mathrm{Fe}(\mathrm{CN})_{6}\right]$ in $1 \mathrm{M} \mathrm{KCl}$ aqueous solution at a $0.1 \mathrm{~V} / \mathrm{s}$ scan rate (left panel) and its magnification (right).

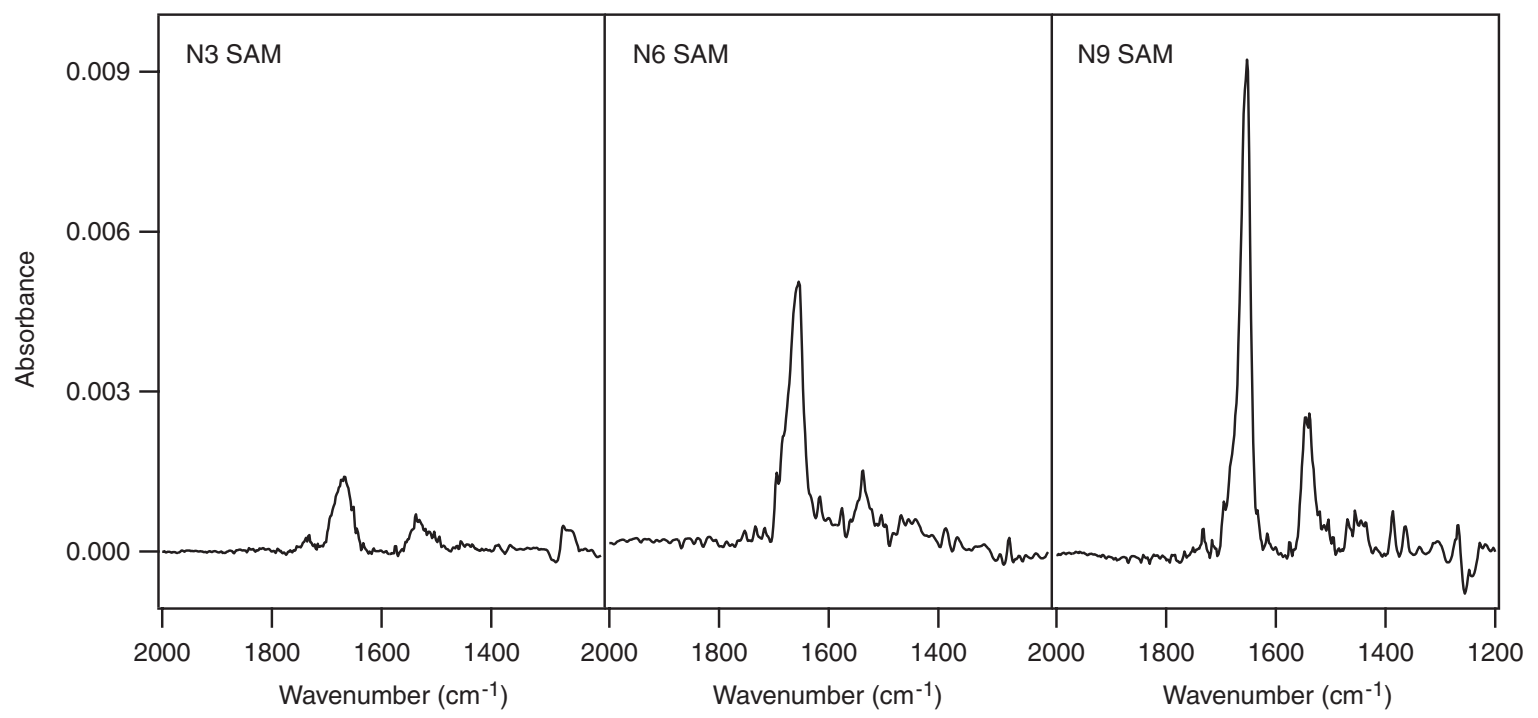

Figure 5. IRRAS spectra of the N3, N6, and N9 SAMs.

form (24/1) for N6, and chloroform/TFE/HFIP (40/1/1) for N9. The cyclic voltammetry revealed that the N6 SAM is wellpacked while the N3 and N9 SAMs have defect sites. To fill up the voids of monolayer, the SAMs were further treated with dodecanethiol vapor at $80^{\circ} \mathrm{C}$. The cyclic voltammograms of a bare gold and the SAM-modified substrates in a $\mathrm{K}_{4}\left[\mathrm{Fe}(\mathrm{CN})_{6}\right]$ aqueous solution are shown in Figure 4 . The redox reaction of ferricyanide/ferrocyanide which was seen for bare gold was completely blocked by the peptide layer, showing that the layer is free from defects which allow diffusion of ferrocyanide ions to reach the gold surface. The magnified voltammograms (Figure 4 right) showed that the capacitic current was larger in the N3 SAM compared to the other SAMs, suggesting the N3 SAM still has small defects to incorporate water molecules or ionic species. The capacitances were estimated to be $13.4 \mu \mathrm{F} /$ $\mathrm{cm}^{2}$ for the N3 SAM, $3.9 \mu \mathrm{F} / \mathrm{cm}^{2}$ for the N6 SAM, and $3.1 \mu \mathrm{F} /$ $\mathrm{cm}^{2}$ for the N9 SAM, respectively. The latter two capacitances are comparable to the capacitance of well-packed alkanethiol SAMs $\left(1-5 \mu \mathrm{F} / \mathrm{cm}^{2}\right){ }^{53-56}$

The monolayer thicknesses were determined by ellipsometry. The thicknesses were $19 \AA$ ( $18 \AA$ before dodecanethiol treatment) for the N3 SAM, $33 \AA$ ( $33 \AA$ ) for the N6 SAM, and $47 \AA$ ( $41 \AA$ ) for the N9 SAM, respectively. The increase of the thickness in the N3 and N9 SAMs with the dodecanethiol treatment indicates the filling of the monolayer defects, because a poorly-packed monolayer gives a smaller thickness than the actual thickness due to its lower refractive index. Molecular orientation of SAMs was studied by IRRAS. The results are shown in Figure 5. The tilt angles of helix axis from the surface normal were determined to be $47^{\circ}\left(43^{\circ}\right.$ before dodecanethiol treatment) for the N3 SAM, $39^{\circ}\left(36^{\circ}\right)$ for the N6 SAM, and $36^{\circ}\left(33^{\circ}\right)$ for the N9 SAM, respectively. The 
molecular orientation was not much changed by the dodecanethiol treatment, and the slight increase of the tilt angles suggests reorganization of the peptides by heating. The monolayer thickness can be given by the molecular length multiplied by cos(tilt angle). The molecular lengths were calculated to be $25 \AA$ for N3, $43 \AA$ for N6, and $61 \AA$ for N9. The estimated monolayer thicknesses are $17 \AA$ for $\mathrm{N} 3,33 \AA$ for N6, and $49 \AA$ for N9, respectively. These thicknesses are in excellent agreement with the ellipsometry results ( $19 \AA$, $33 \AA$, and $47 \AA$ ), clearly indicating formation of a well-defined monolayer on the surface.

\section{Photocurrent Generation}

Photocurrent generation was studied with the dodecanethioltreated SAMs by irradiation with a $280 \mathrm{~nm}$ light in an aqueous solution containing a sacrifice electron donor, TEOA. The time courses of the currents for the respective SAMs are shown in Figure 6. An anodic photocurrent was generated in response of photoirradiation in each SAM. The photocurrent increased as the peptide becomes longer, and the current intensities were $0.23 \mathrm{nA}$ for the N3 SAM, $0.48 \mathrm{nA}$ for the N6 SAM, and $0.72 \mathrm{nA}$ for the N9 SAM, respectively. The mechanism for the anodic photocurrent generation is explained by an energy diagram shown in Figure 7. Without energy migration among the Nap groups, the process is initiated by excitation of the Nap group at the $C$-terminal exposed to the aqueous phase. When the Nap group is photoexcited, it accepts an electron from TEOA to form an anion radical of the Nap group, which then directly transfers an electron to gold, or hops among the Nap groups to come close to gold and then transfers an electron. When the peptide is long, the electron hopping should be dominant over the direct electron transfer. Another process via a cation radical of a Nap group can lead to photocurrent generation as well, in which the photoexcited Nap group in close proximity to gold first transfers an electron to gold to form the Nap cation radical, which is then reduced by TEOA. Since the electron transfer from TEOA to the excited Nap or to the Nap cation radical should be very fast in case of their close location at the interface between water and the SAM, the rate-determining step is either electron transfer from the Nap anion radical to gold including electron hopping processes among the Nap

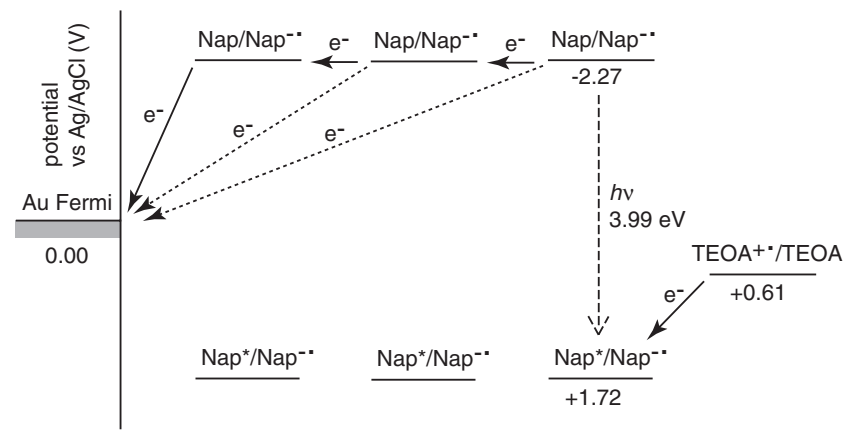

Figure 7. Energy diagram for anodic photocurrent generation via Nap anion radical in the N3 SAM.

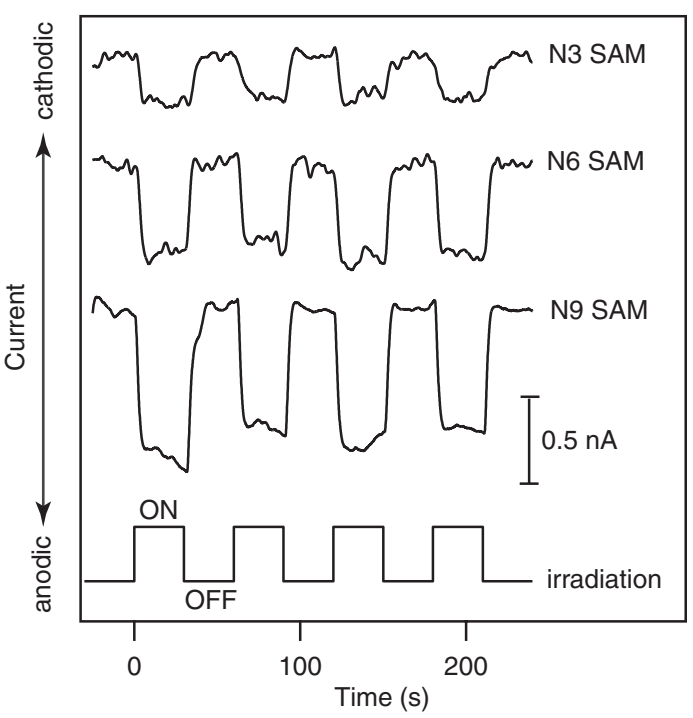

Figure 6. Time profile of current for the N3, N6, and N9 SAMs in a $0.05 \mathrm{M}$ TEOA and $0.1 \mathrm{M} \mathrm{NaSO}_{4}$ aqueous solution upon photoirradiation with a $280 \mathrm{~nm}$ light.

groups or hole transfer from the Nap cation radical to the Nap group at the $C$-terminal exposed to water. The former electron transfer process should be prevailing in the present case, because in the latter process the back electron transfer from gold to the Nap cation radical is competitive to the hole transfer. Therefore, the process via the Nap anion radical is dominant in these molecular systems. The quantum yields for all the photons absorbed by the Nap groups are $3.1 \%$ for the N3 SAM, $2.5 \%$ for the N6 SAM, and $2.4 \%$ for the N9 SAM, respectively. Assuming there is no energy migration among the Nap groups, only excitation of the Nap group at the $C$-terminal can accept an electron from TEOA and lead to the anodic photocurrent generation. Therefore, the quantum yields for the photons absorbed by that Nap group are $9.3(3.1 \times 3) \%, 15.0$ $(2.5 \times 6) \%$, and $21.6(2.4 \times 9) \%$, respectively. These relatively high quantum yields are surprising. Especially in the N9 SAM, the Nap group at the $C$-terminal is at least $40 \AA$ distant from the gold surface. This finding suggests efficient electron hopping among the Nap groups enables a long-range electron transfer.

\section{Theoretical Simulations}

Simulations of anodic photocurrent generation were carried out to quantitatively discuss the effects of electron hopping and energy migration among the Nap groups. For example, the model used in the simulation for the N3 SAM is schematically shown in Figure 8. N3 has three Nap groups, that are labeled from the $N$-terminal (near gold) as $1^{*}, 2^{*}$, and $3^{*}$ for the excited state while $1^{-}, 2^{-}$, and $3^{-}$for the anion radical. The temporal differentiations of the numbers of the respective intermediates are expressed as eq 1.

$$
\begin{aligned}
\mathrm{d}\left[1^{*}\right] / \mathrm{dt}= & k_{\mathrm{ex}}+k_{\mathrm{em}}\left[2^{*}\right]-\left(k_{\mathrm{n}}+k_{1 \mathrm{q}}+k_{\mathrm{em}}+k_{1 \mathrm{~d}}\right)\left[1^{*}\right] \\
\mathrm{d}\left[2^{*}\right] / \mathrm{dt}= & k_{\mathrm{ex}}+k_{\mathrm{em}}\left(\left[1^{*}\right]+\left[3^{*}\right]\right) \\
& -\left(k_{\mathrm{n}}+k_{2 \mathrm{q}}+2 k_{\mathrm{em}}+k_{2 \mathrm{~d}}\right)\left[2^{*}\right]
\end{aligned}
$$



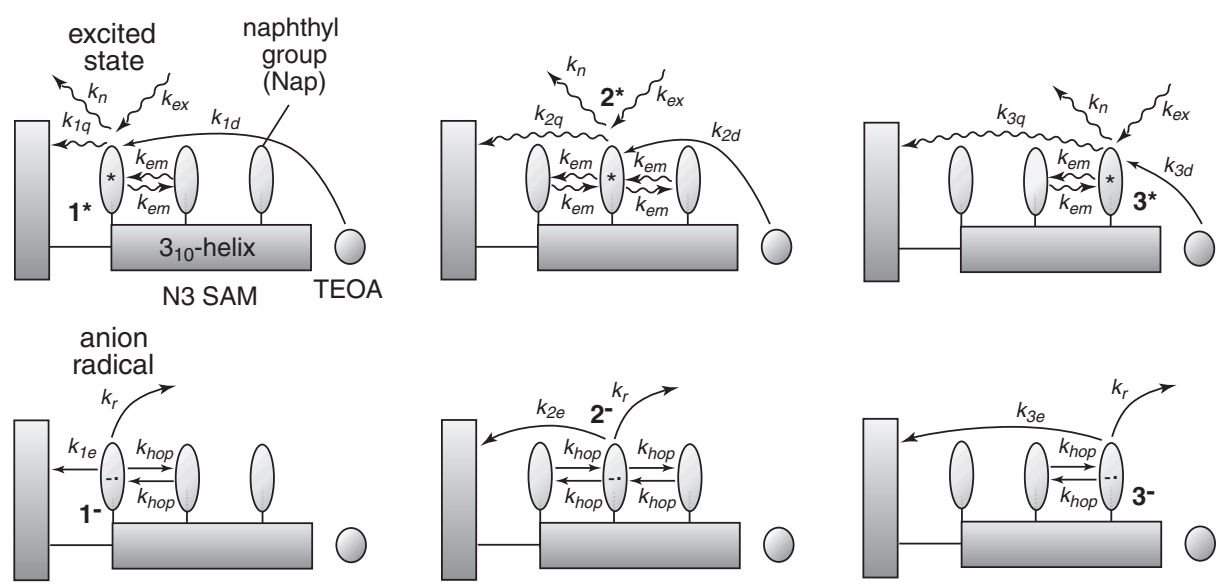

$$
\begin{aligned}
& k_{e x}: \text { excitation } \\
& k_{e m}: \text { energy migration among Naps } \\
& k_{n}: \text { intrinsic deactivation of excited Nap } \\
& k_{i q}: \text { energy transfer from Nap to gold }
\end{aligned}
$$

$$
\begin{aligned}
& \longleftarrow \text { electron transfer process } \\
& k_{i d}: \text { electron transfer from TEOA to Nap } \\
& k_{h o p}: \text { radical hopping among Naps } \\
& k_{i e}: \text { electron transfer from Nap to gold } \\
& k_{r}: \text { deactivation of Nap anion radical }
\end{aligned}
$$

Figure 8. Schematic illustration for theoretical simulations of anodic photocurrent generation by the N3 SAM.

$$
\begin{aligned}
\mathrm{d}\left[3^{*}\right] / \mathrm{dt}= & k_{\mathrm{ex}}+k_{\mathrm{em}}\left[2^{*}\right]-\left(k_{\mathrm{n}}+k_{3 \mathrm{q}}+k_{\mathrm{em}}+k_{3 \mathrm{~d}}\right)\left[3^{*}\right] \\
\mathrm{d}\left[1^{-}\right] / \mathrm{dt}= & k_{1 \mathrm{~d}}\left[1^{*}\right]+k_{\mathrm{hop}}\left[2^{-}\right]-\left(k_{1 \mathrm{e}}+k_{\mathrm{hop}}+k_{\mathrm{r}}\right)\left[1^{-}\right] \\
\mathrm{d}\left[2^{-}\right] / \mathrm{dt}= & k_{2 \mathrm{~d}}\left[3^{*}\right]+k_{\mathrm{hop}}\left(\left[1^{-}\right]+\left[3^{-}\right]\right) \\
& -\left(k_{2 \mathrm{e}}+2 k_{\mathrm{hop}}+k_{\mathrm{r}}\right)\left[2^{-}\right] \\
\mathrm{d}\left[3^{-}\right] / \mathrm{dt}= & k_{3 \mathrm{~d}}\left[3^{*}\right]+k_{\mathrm{hop}}\left[2^{-}\right]-\left(k_{3 \mathrm{e}}+k_{\mathrm{hop}}+k_{\mathrm{r}}\right)\left[3^{-}\right]
\end{aligned}
$$

The respective rate constants are excitation $\left(k_{\mathrm{ex}}\right)$, energy migration among Nap groups $\left(k_{\mathrm{em}}\right)$, intrinsic deactivation including radiative and nonradiative processes $\left(k_{\mathrm{n}}\right)$, energy transfer to gold $\left(k_{\mathrm{iq}}\right)$, and electron transfer from TEOA to Nap $\left(k_{\text {id }}\right)$ for the excite state, while for the anion radical, electron hopping among Nap groups $\left(k_{\text {hop }}\right)$, electron transfer from Nap anion radical to gold $\left(k_{\mathrm{ie}}\right)$, and intrinsic deactivation of the anion radical $\left(k_{\mathrm{r}}\right)$. The rate constants containing "i" are dependent on the position of Nap group. Steady-state approximation was applied to all the equations, that is all the temporal differentiations are zero, and the six simultaneous equations were solved to afford the concentrations of the intermediates in the steady state. Finally, the photocurrent is given by eq 2 .

$$
\begin{aligned}
& \text { photocurrent }(\mathrm{A}) \\
& \quad=\left(k_{1 \mathrm{e}}\left[1^{-}\right]+k_{2 \mathrm{e}}\left[2^{-}\right]+k_{3 \mathrm{e}}\left[3^{-}\right]\right) \times 1.6 \times 10^{-19}
\end{aligned}
$$

The rate constants except for $k_{\mathrm{r}}$ were calculated by the Förster equation, ${ }^{39}$ surface energy transfer formalism, ${ }^{57}$ and semiclassical Marcus theory ${ }^{8,58-60}$ with parameters in the literature. ${ }^{5,61}$ The $k_{\mathrm{r}}$ value is unknown and was used as a free parameter to reproduce the experimental currents. The simulations for N6 and N9 were similarly performed. With setting $k_{\mathrm{r}}=2 \times 10^{9} \mathrm{~s}^{-1}$, the simulations produced the most fitting results to the experimental data.

The simulation results are summarized in Table I. The simulated currents (3rd column in Table I) can only explain consistently the experimental data (2nd column) if $k_{\mathrm{r}}$ is set to
Table I. Simulation results for photocurrent generation by the SAMs including electron hopping $(E H)$ and energy migration (EM) among the Nap groups

\begin{tabular}{ccccc}
\hline SAM & $\begin{array}{c}\text { experimental simulated current } \\
\text { current } \\
(\mathrm{nA})\end{array}$ & $\begin{array}{c}\text { simulated current } \\
\text { with } \mathrm{EH} \text { and EM } \\
(\mathrm{nA})\end{array}$ & $\begin{array}{c}\text { with EM only } \\
(\mathrm{nA})\end{array}$ & $\begin{array}{c}\text { with } \mathrm{EH} \text { only } \\
(\mathrm{nA})\end{array}$ \\
\hline N3 SAM & 0.23 & 0.11 & $3.4 \times 10^{-4}$ & 0.11 \\
N6 SAM & 0.48 & 0.56 & $2.1 \times 10^{-6}$ & 0.56 \\
N9 SAM & 0.72 & 0.69 & $3.2 \times 10^{-13}$ & 0.50 \\
\hline
\end{tabular}

be $2 \times 10^{9} \mathrm{~s}^{-1}$ and both electron hopping (EH) and energy migration (EM) among the Nap groups are assumed operative. On the other hand, with only energy migration taken into account, the simulated currents were too small (4th column). These results indicate that the electron hopping among the Nap groups is essential for efficient photocurrent generation. Meanwhile, simulations with only electron hopping assumed gave almost the same results (5th column) as those with both electron hopping and energy migration assumed (3rd column). A slight enhancement by energy migration was observed only for the N9 SAM. This finding suggests that the direction of energy migration is random, and thus energy migration toward the Nap group at the $C$-terminal promoting photocurrent generation is nearly counterbalanced by energy migration toward gold suppressing photocurrent generation.

The yields of the Nap anion radical production at the $C$-terminal were calculated by an approximated equation of $100 \times k_{\text {id }} /\left(k_{\text {id }}+k_{\mathrm{n}}+k_{\text {iq }}\right)(\mathrm{i}=3,6$, and 9 for the N3, N6, and N9 SAMs) to be $6.7 \%$ for the N3 SAM, $51.4 \%$ for the N6 SAM, and $77.1 \%$ for the N9 SAM, respectively. This result indicates that separation of the terminal Nap group from gold by chain elongation effectively suppresses photoenergy dissipation by the energy transfer to gold. On the other hand, the efficiencies of electron transport from the Nap group at the 
$C$-terminal to gold were calculated from the quantum yields for photocurrent generation for the photons absorbed by the Nap group at the $C$-terminal and the yields of Nap anion radical production. The efficiencies are $56.4 \%$ for the N3 SAM, 33.3\% for the N6 SAM, and $26.3 \%$ for the N9 SAM. This slow decay on distance clearly indicates that the electron hopping among the Nap groups is amazingly efficient. If there was no electron hopping, the electron transfer rate would drop by $2 \times 10^{9}$ times from N3 to $\mathrm{N} 9\left(2 \times 10^{9}=\exp [(27-9) \times 2 \times 0.6]\right)$. The rate constant of electron hopping in the simulation was $5.6 \times$ $10^{10} \mathrm{~s}^{-1}$, which should be the result of regular close arrangement of the Nap groups. Finally, these simulation results clearly demonstrate that the electron hopping is facilitated by the linearly-arranged Nap groups along the helix and is essential for electron transfer from the distant Nap group to gold over a long distance, resulting in the efficient anodic photocurrent generation in the longer peptide monolayer.

In conclusion, three different lengths of $3_{10}$-helical peptides carrying naphthyl groups at the side chains in a linear arrangement and having a disulfide group at the $N$-terminal were synthesized. Absorption and fluorescence spectroscopy in solution showed that there is no interaction between neighboring naphthyl groups either in the ground state or in the excited state. The $33_{10}$-helical conformation was confirmed by circular dichroism spectroscopy and computational geometry optimization. The peptide was self-assembled on gold by an Au-S linkage and then monolayer defects were filled up with dodecanethiol. Cyclic voltammetry, ellipsometry, and infrared reflection-absorption studies revealed that the monolayers were free from defects and well-defined with vertical orientation. Upon photoexcitation of the naphthyl group in an aqueous solution with an electron donor, all the monolayers generated an anodic photocurrent by photoinduced electron transfer from the electron donor via the naphthyl groups to gold. The longest 27 mer peptide carrying nine naphthyl groups generated the largest photocurrent. Simulations of photocurrent generation taking all plausible reactions into account successfully demonstrate that quenching of the excited Nap group by energy transfer to gold is effectively suppressed by separation from gold, and efficient electron hopping among the naphthyl groups facilitates long-range electron transfer from the distant Nap group to gold, leading to efficient photocurrent generation. The simulations also suggest that the effect of energy migration on photocurrent generation is minor because the direction of energy migration is random. Then, one idea comes to us to utilize more efficiently photoenergy transfer among the chromophores with introducing an energy acceptor for the naphthyl groups at the $C$-terminal. Directional energy transfer from the naphthyl group to the acceptor will increase the yield of radical production and promote photocurrent generation. That system including photoenergy harvesting and electron transport will be a more sophisticated mimic of natural photosynthesis. Construction of such a system is underway.

Acknowledgment. This work is partly supported by Grantin-Aids for Young Scientists B (16750098), for Exploratory
Research (17655098), and for Scientific Research B (15350068), and Global COE program, International Center for Integrated Research and Advanced Education in Materials Science, from the Ministry of Education, Culture, Sports, Science, and Technology, Japan.

Received: March 5, 2008 Accepted: April 19, 2008 Published: June 11, 2008

\section{REFERENCES}

1. J. Deisenhofer and H. Michel, Angew. Chem., Int. Ed., 28, 829 (1989).

2. M. R. Wasielewski, Chem. Rev., 92, 435 (1992).

3. W. G. J. Hol, P. T. Vanduijnen, and H. J. C. Berendsen, Nature, 273, 443 (1978).

4. W. G. J. Hol, Prog. Biophys. Mol. Biol., 45, 149 (1985).

5. M. Sisido, S. Hoshino, H. Kusano, M. Kuragaki, M. Makino, H. Sasaki, T. A. Smith, and K. P. Ghiggino, J. Phys. Chem. B, 105, 10407 (2001).

6. S. Sek, A. Misicka, K. Swiatek, and E. Maicka, J. Phys. Chem. B, 110, 19671 (2006).

7. K. Kitagawa, T. Morita, and S. Kimura, J. Phys. Chem. B, 109, 13906 (2005).

8. J. F. Smalley, H. O. Finklea, C. E. D. Chidsey, M. R. Linford, S. E. Creager, J. P. Ferraris, K. Chalfant, T. Zawodzinsk, S. W. Feldberg, and M. D. Newton, J. Am. Chem. Soc., 125, 2004 (2003).

9. B. Q. Xu and N. J. J. Tao, Science, 301, 1221 (2003).

10. K. Kitagawa, T. Morita, and S. Kimura, Thin Solid Films, 509, 18 (2006).

11. T. Morita and S. Lindsay, J. Am. Chem. Soc., 129, 7262 (2007).

12. E. Galoppini and M. A. Fox, J. Am. Chem. Soc., 118, 2299 (1996).

13. M. A. Fox and E. Galoppini, J. Am. Chem. Soc., 119, 5277 (1997).

14. T. Morita, S. Kimura, S. Kobayashi, and Y. Imanishi, J. Am. Chem. Soc., 122, 2850 (2000).

15. S. Yasutomi, T. Morita, Y. Imanishi, and S. Kimura, Science, 304, 1944 (2004).

16. S. Yasutomi, T. Morita, and S. Kimura, J. Am. Chem. Soc., 127, 14564 (2005).

17. S. Yamada, H. Kohrogi, and T. Matsuo, Chem. Lett., 639 (1995).

18. S. Yamada, Y. Koide, and T. Matsuo, J. Electroanal. Chem., 426, 23 (1997).

19. K. Uosaki, T. Kondo, X. Q. Zhang, and M. Yanagida, J. Am. Chem. Soc., 119, 8367 (1997).

20. T. Kondo, M. Yanagida, S. Nomura, T. Ito, and K. Uosaki, J. Electroanal. Chem., 438, 121 (1997).

21. H. Imahori, H. Norieda, S. Ozawa, K. Ushida, H. Yamada, T. Azuma, K. Tamaki, and Y. Sakata, Langmuir, 14, 5335 (1998).

22. H. Imahori, T. Azuma, S. Ozawa, H. Yamada, K. Ushida, A. Ajavakom, H. Norieda, and Y. Sakata, Chem. Commun., 557 (1999).

23. H. Imahori, T. Azuma, A. Ajavakom, H. Norieda, H. Yamada, and Y. Sakata, J. Phys. Chem. B, 103, 7233 (1999).

24. T. Morita, S. Kimura, S. Kobayashi, and Y. Imanishi, Chem. Lett., 676 (2000).

25. H. Imahori, H. Yamada, Y. Nishimura, I. Yamazaki, and Y. Sakata, J. Phys. Chem. B, 104, 2099 (2000).

26. T. Kondo, M. Yanagida, X. Q. Zhang, and K. Uosaki, Chem. Lett., 964 (2000).

27. H. Imahori, H. Norieda, H. Yamada, Y. Nishimura, I. Yamazaki, Y. Sakata, and S. Fukuzumi, J. Am. Chem. Soc., 123, 100 (2001).

28. P. K. Sudeep, B. I. Ipe, K. G. Thomas, M. V. George, S. Barazzouk, S. Hotchandani, and P. V. Kamat, Nano Lett., 2, 29 (2002).

29. A. Nomoto and Y. Kobuke, Chem. Commun., 1104 (2002).

30. F. B. Abdelrazzaq, R. C. Kwong, and M. E. Thompson, J. Am. Chem. 
Soc., 124, 4796 (2002).

31. K. G. Thomas and P. V. Kamat, Acc. Chem. Res., 36, 888 (2003).

32. E. Soto, J. C. MacDonald, C. G. F. Cooper, and G. McGimpsey, J. Am. Chem. Soc., 125, 2838 (2003).

33. K. Yanagisawa, T. Morita, and S. Kimura, J. Am. Chem. Soc., 126, 12780 (2004).

34. E. Benedetti, A. Bavoso, B. Diblasio, V. Pavone, C. Pedone, M. Crisma, G. M. Bonora, and C. Toniolo, J. Am. Chem. Soc., 104, 2437 (1982).

35. C. Toniolo, G. M. Bonora, V. Barone, A. Bavoso, E. Benedetti, B. Diblasio, P. Grimaldi, F. Lelj, V. Pavone, and C. Pedone, Macromolecules, 18, 895 (1985).

36. I. L. Karle, M. Sukumar, and P. Balaram, Proc. Natl. Acad. Sci. U.S.A., 83, 9284 (1986).

37. C. Toniolo and E. Benedetti, Trends Biochem. Sci., 16, 350 (1991).

38. D. F. Kennedy, M. Crisma, C. Toniolo, and D. Chapman, Biochemistry, 30, 6541 (1991).

39. T. Forster, Discuss. Faraday Soc., 7 (1959).

40. Z. J. Donhauser, B. A. Mantooth, K. F. Kelly, L. A. Bumm, J. D. Monnell, J. J. Stapleton, D. W. Price, A. M. Rawlett, D. L. Allara, J. M. Tour, and P. S. Weiss, Science, 292, 2303 (2001).

41. H. U. Gremlich, U. P. Fringeli, and R. Schwyzer, Biochemistry, 22, 4257 (1983).

42. Y. Miura, S. Kimura, Y. Imanishi, and J. Umemura, Langmuir, 14, 6935 (1998)

43. M. Tsuboi, J. Polym. Sci., 59, 139 (1962).

44. E. Benedetti, B. Di Blasio, V. Pavone, C. Pedone, A. Santini, M. Crisma, and C. Toniolo, in "Molecular Conformation and Biological Interactions,” P. Balaram and S. Ramaseshan, Ed., Indian Academy of Science, Bangalore, 1991, pp 497.

45. C. G. Hatchard and C. A. Parker, Proc. R. Soc. London, A, 235, 518
(1956).

46. H. Du, R. C. A. Fuh, J. Z. Li, L. A. Corkan, and J. S. Lindsey, Photochem. Photobiol., 68, 141 (1998).

47. M. Sisido, S. Egusa, and Y. Imanishi, J. Am. Chem. Soc., 105, 4077 (1983).

48. M. Sisido, S. Egusa, and Y. Imanishi, J. Am. Chem. Soc., 105, 1041 (1983).

49. R. W. Woody, J. Chem. Phys., 49, 4797 (1968)

50. M. Sisido and Y. Imanishi, Macromolecules, 18, 890 (1985).

51. Y. Inai and T. Hirabayashi, Biopolymers, 59, 356 (2001).

52. Y. Inai, T. Oshikawa, M. Yamashita, T. Hirabayashi, and T. Hirako, Biopolymers, 58, 9 (2001).

53. M. D. Porter, T. B. Bright, D. L. Allara, and C. E. D. Chidsey, J. Am. Chem. Soc., 109, 3559 (1987).

54. C. A. Widrig, C. Chung, and M. D. Porter, J. Electroanal. Chem., 310, 335 (1991).

55. C. Miller, P. Cuendet, and M. Gratzel, J. Phys. Chem., 95, 877 (1991).

56. A. L. Plant, Langmuir, 9, 2764 (1993).

57. C. S. Yun, A. Javier, T. Jennings, M. Fisher, S. Hira, S. Peterson, B. Hopkins, N. O. Reich, and G. F. Strouse, J. Am. Chem. Soc., 127, 3115 (2005).

58. R. A. Marcus and N. Sutin, Biochim. Biophys. Acta, 811, 265 (1985).

59. P. Siddarth and R. A. Marcus, J. Phys. Chem., 94, 2985 (1990)

60. D. M. Adams, L. Brus, C. E. D. Chidsey, S. Creager, C. Creutz, C. R. Kagan, P. V. Kamat, M. Lieberman, S. Lindsay, R. A. Marcus, R. M. Metzger, M. E. Michel-Beyerle, J. R. Miller, M. D. Newton, D. R. Rolison, O. Sankey, K. S. Schanze, J. Yardley, and X. Y. Zhu, J. Phys. Chem. B, 107, 6668 (2003).

61. G. J. Kavarnos and N. J. Turro, Chem. Rev., 86, 401 (1986). 